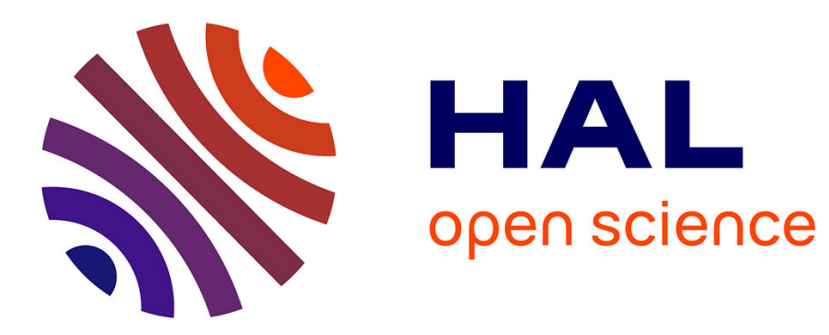

\title{
Considering Stress-Phase Transformation Interactions in the Calculation of Heat Treatment Residual Stresses
}

\author{
S. Denis
}

\section{To cite this version:}

S. Denis. Considering Stress-Phase Transformation Interactions in the Calculation of Heat Treatment Residual Stresses. Journal de Physique IV Proceedings, 1996, 06 (C1), pp.C1-159-C1-174. 10.1051/jp4:1996116 . jpa-00254148

HAL Id: jpa-00254148

https://hal.science/jpa-00254148

Submitted on 1 Jan 1996

HAL is a multi-disciplinary open access archive for the deposit and dissemination of scientific research documents, whether they are published or not. The documents may come from teaching and research institutions in France or abroad, or from public or private research centers.
L'archive ouverte pluridisciplinaire HAL, est destinée au dépôt et à la diffusion de documents scientifiques de niveau recherche, publiés ou non, émanant des établissements d'enseignement et de recherche français ou étrangers, des laboratoires publics ou privés. 


\title{
Considering Stress-Phase Transformation Interactions in the Calculation of Heat Treatment Residual Stresses
}

\author{
S. Denis \\ Laboratoire de Sciences et Génie des Matériaux Métalliques, URA 159 du CNRS, Ecole des Mines de \\ Nancy, Parc de Saurupt, 54042 Nancy cedex, France
}

\begin{abstract}
The models for describing stress-phase transformation interactions (transformation plasticity and the effect of stress on transformation kinetics) are reviewed. It is shown that the macroscopic constitutive law that is generally used in the calculation of heat treatment residual stresses in steels allows to describe well the thermomechanical behaviour of the material in its transformation range. An analysis of the role of these interactions on the stress/strain evolutions during the heat treatment of a piece and on the residual stress states is proposed based on numerical simulations.
\end{abstract}

\section{INTRODUCTION}

The heat treatment of metallic alloys generally involves thermal, metallurgical and mechanical phenomena and their couplings. Indeed, during a heat treatment (quenching, surface hardening, thermochemical treatment) the alloy undergoes temperature variations and phase transformations. The resulting changes in density give rise to internal stresses in the piece. Only first order stresses will be considered here. In addition, the phase transformation affects the temperature evolutions through transformation enthalpy and changes in thermophysical properties and the stresses affect the kinetics of the phase transformation. Moreover, the phase transformation modifies the thermomechanical behaviour of the material through transformation plasticity and through the change of mechanical properties.

As heat treatment processes are difficult to control and optimize, big efforts have been made during the last fifteen years in order to predict the results of the heat treatment (microstructures and hardness, residual stresses and distorsions of the piece). The above mentioned phenomena have to be modelled and further introduced in mechanical calculations by finite elements. This work has been particularly developed for steels.

Considering the great complexity of the metallurgical and thermomechanical behaviour of steels, it has been considered that the only way to achieve a quantitative prediction of internal stresses and strains in a steel part during heat treatment is to establish macroscopic models based on experimental data.

The aim of this paper is firstly to review how the stress-phase transformation interactions (the effect of stress on transformation kinetics and the transformation plasticity phenomenon) have been modelled for the purpose of residual stress calculations. Then, we will analyse how these models allow to describe the thermomechanical behaviour of the material during phase transformation as it can be measured in a specimen (during a tensile test). Finally, from numerical simulations, we will analyse how the stress-phase transformation interactions affect the development of internal stresses and strains in a piece during heat treatment.

\section{MODELLING OF STRESS-PHASE TRANSFORMATION INTERACTIONS}

When phase transformation takes place under stress different effects are observed : phase transformation kinetics is modified (it will be called "metallurgical" interaction), a transformation plasticity deformation (or transformation induced plasticity) occurs (it will be called "mechanical" interaction) and the transformation mechanism can be modified. These effects have been reviewed for different phase transformations which occur in steels (diffusion dependent and martensitic ones) both from the point of view of the mechanisms involved, the experimental determination and the modelling [1-5].

It should be underlined that the material in a piece undergoing a heat treatment is generally submitted to triaxial stress states and to small plastic strains (typically less than 1\%). Thus, in the following we shall 
only recall the phenomena that may occur under such conditions and give a synthesis of the models used presently for the calculation of internal stresses.

\subsection{Metallurgical interaction}

\subsubsection{Phenomena}

The present knowledge concerns essentially the effect of hydrostatic pressure or uniaxial stresses on the phase transformation:

- under hydrostatic pressure, the equilibrium diagram is modified and the transformation kinetics are slowered. For the martensitic transformation, a decrease in Ms temperature is observed with increasing pressure. During the austenite decomposition, the isothermal transformation curves (IT diagrams) and the continuous cooling transformation curves (CCT diagrams) are shifted towards lower temperatures and longer times.

- under uniaxial stresses (tension or compression), the kinetics of diffusional decomposition of austenite (ferritic and pearlitic transformation) are accelerated (due to an increase in nucleation rate). The same is true when plastic strain has occured in austenite prior to the transformation. Concerning martensitic transformation, for stresses lower than the yield stress of austenite, only Ms temperature increases. A compressive stress is less effective than a tensile stress (this behaviour is explained by the Patel and Cohen model). A plastic strain in austenite (in the range 0-5\%) before martensitic transformation leads to a decrease in Ms temperature which is more significant as the deformation occurs at a temperature near Ms (this effect has to be related to strain hardening of austenite).

\subsubsection{Modelling}

Only a few models have been developed in order to take into account the effect of the stress/strain states generated during cooling in a piece on the kinetics of the phase transformations $[6,7,8]$.

In the calculation of internal stresses, the progress of martensitic transformation is generally described by a Koistinen Marburger type law :

$$
\mathrm{ym}_{\mathrm{m}}=\mathrm{y}_{\gamma}\left(1-\exp \left(-\mathrm{k}\left(\mathrm{M}_{\mathrm{S}}-\mathrm{T}\right)\right)\right.
$$

where $y_{m}$ is the volume fraction of martensite, $y_{\gamma}$ the volume fraction of austenite, $\mathrm{T}$ the temperature and $\mathrm{k}$ a constant.

It has been assumed, on one hand that the effect of the stress/strain state only results in a variation in $\mathbf{M}_{\mathrm{S}}$ temperature and on the other hand that alone the internal stress state affects the $\mathbf{M}_{\mathbf{S}}$ temperature. Indeed, it can be estimated that an accumulated plastic strain in austenite during cooling of about $1 \%$ would lead to a decrease of $M_{S}$ temperature of a few degrees whereas a stress state close to the yield stress of austenite can lead to an increase of $30^{\circ} \mathrm{C}$ [3].

In order to take into account that both shear and normal components of the stress affects $\mathrm{M}_{\mathbf{S}}$ temperature, Inoue [6] proposed a model in which the change in $M_{S}$ temperature is related to the mean stress $\sigma_{\mathrm{m}}$ and to the second invariant of the stress deviator tensor $\mathrm{J}_{2}$ :

$$
\Delta \mathrm{M}_{\mathrm{S}}=\mathrm{A} \sigma_{\mathrm{m}}+\mathrm{BJ}_{2}{ }^{1 / 2}
$$

$\mathrm{A}$ and $\mathrm{B}$ are material dependent coefficients that are determined experimentally [1].

Concerning diffusion dependent transformations, the effect of stress/strain states on the isothermal kinetics has been described through a shift of the IT curves in the time scale. As before, it has been assumed that the effect of plastic strain is negligible when compared to the effect of the stress. Moreover, the effect of the mean stress can be neglected when compared to the effect of the stress deviator (at least for middle size pieces in which the mean stress does not exceed a few hundred MPa during quenching for example) [7]. Considering that the isothermal transformation is divided into an incubation period followed by the progression of the transformation that is described by a Johnson-Mehl-Avrami law [9], we have taken into account the effect of stress in the following manner [7] :
for the incubation period :

$$
\tau_{\mathrm{IT} \sigma}=\tau_{\mathrm{IT}}\left(1+\mathrm{D}_{\mathrm{k}}\right) \text { with } \mathrm{D}_{\mathrm{k}}=\mathrm{gk}_{\mathrm{k}}\left(\sigma_{\mathrm{e}}\right)
$$
for the growth period:

$$
y_{k}=y_{\operatorname{maxk}}\left(1-\exp -b_{k}\left(t /\left(1+D_{k}\right)\right)^{n_{k}}\right)
$$

$\tau_{\mathrm{IT}}$ is the isothermal incubation period (subscript $\sigma$ denotes "with effect of stress"), yk is the volume fraction of constituent $\mathrm{k}$ ( $\mathrm{ymaxk}$ the maximum value), $\mathrm{n}_{\mathrm{k}}$ and $\mathrm{b}_{\mathrm{k}}$ are temperature dependent coefficients, 
$t$ the time ( $t=0$ is the end of incubation period), $D_{k}$ is the shift of IT curves, $g_{k}$ is an experimental function, $\sigma_{\mathrm{e}}$ is the Von Mises equivalent stress.

A different assumption has been proposed by Inoue [6] in which the shift of IT curves is only a function of the mean stress.

For bainitic transformation, a model taking into account a variation of $B$ s temperature with the stress state (in the same way as for Ms temperature) and a modification of the transformation kinetics (in the same way as for pearlitic transformation) can be proposed [8].

\subsection{Mechanical interaction}

\subsubsection{Phenomenon}

Transformation plasticity is a deformation that appears for a transforming material under an applied stress even for stresses lower than the yield stress of the phases. This deformation is generally attributed to two basic mechanisms

- the anisotropic plastic accommodation of the transformation strain. For transformations that occur with a volume change alone (ferritic and pearlitic transformation in steels for example), this mechanism is the only one to be considered.

- the orientation of the product phase by the stress state. This mechanism intervenes when transformation strain has a shear component.

Both mechanisms are effective for martensitic transformation in steels $[5,10]$.

Most of the studies concern constant applied stresses during the transformation. They generally show a linear relationship between transformation plasticity and the applied stress for stresses lower than the yield stress of the parent phase and for a fully transformed specimen. The variation of transformation plasticity with the progress of transformation has been found as linear for pearlitic and ferritic transformations of steels $[11,12]$. For martensitic transformation, this variation is generally found to be nonlinear with a high slope at the very beginning of the transformation due to the orientation effect (mechanism 2) and to plastic accommodation (mechanism 1) and a decrease of this slope as the orientation effect decreases [5, 10]. Moreover, the nonlinear relationship between transformation plasticity and the applied stress at given martensite contents has been clearly analysed [5]. The behaviour during bainitic transformation is found similar to the one during martensitic transformation as shown in some recent studies $[13,14]$.

\subsubsection{Modelling}

In the past, different models have been developed for describing transformation plasticity.They were based on either one or the other above mentioned mechanisms. A review can be found in [4]. More recently, micromechanical approaches in which both mechanisms are considered for martensitic transformation have been developed [15-18].

For the purpose of calculating internal stresses during heat treatment, mainly a phenomenological approach has been used in which the evolution law for transformation plasticity has been written from experiments. Under uniaxial stresses (tension or compression) transformation plasticity strain has been assumed of the form :

$$
\varepsilon^{\mathrm{tp}}=\mathrm{K} \sigma \mathrm{f}_{\mathrm{k}}\left(\mathrm{yk}_{\mathrm{k}}\right)
$$

where constant $\mathrm{K}$ and function $\mathrm{f}_{\mathrm{k}}$ are both determined experimentally.

For triaxial stress states, it has been assumed that the same relations hold for transformation plasticity strains as for classical plastic strains (Von Mises associated flow rule) i.e. the transformation plasticity strain rate is proportional to the stress deviator $[19,20]$. But since transformation plasticity appears as soon as transformation starts even though the stress is very small, it has been supposed that no yield criterion needs to be verified. The following expression [20] is now used by many authors :

$$
\dot{\varepsilon}_{\mathrm{ij}} \mathrm{tp}^{\mathrm{p}}=3 / 2 \mathrm{Kf} \mathrm{k}^{\prime}\left(\mathrm{yk}_{\mathrm{k}} \mathrm{yk}_{\mathrm{k}} \mathrm{sij}\right.
$$

$s_{i j}$ are the components of the stress deviator tensor.

(Let us point out that the progress of transformation $\mathrm{yk}_{\mathrm{k}}$ has to be considered stress state dependent (see 2.1.2)).

As an alternative, Hamata et al. [21] proposed to use a power law of the stress in the expression of $\varepsilon^{\text {tp }}$ and derived a transformation "viscoplasticity" strain by using an analogy with the theory of viscoplasticity. 
More recently, Videau et al [22] obtained an expression of transformation plasticity by using also viscoplasticity theory. The authors introduce strain hardening effects and propose a proportionality of the transformation plasticity strain with an effective stress i.e. (sij - Xij) where $\mathrm{X}_{\mathrm{ij}}$ represents an "internal" stress (it is analogous to the introduction of a back stress in classical plasticity).

It must be underlined that all these expressions are supposed to be valid for the different transformations occuring during a heat treatment (diffusion dependent and martensitic ones) whatever the mechanisms involved.

It has to be mentioned that Leblond [23] has brought a theoritical justification for proportionality between transformation plasticity and stress deviator (or effective stress by considering kinematic hardening) by developing a model of the thermomechanical behaviour of a two phase transforming material. The author considers only mechanism 1 (plastic accommodation) to be at the origin of transformation plasticity and only the volume change associated with the transformation. In this model, explicit formula are obtained for constant $\mathrm{K}$ and function $\mathrm{f}$. This model takes also into account a deviation from linearity for high applied stresses. In a later work, Fischer [24] formulated also the transformation plasticity strain as linearly related to the stress deviator for a martensitic transformation by considering only mechanism 1 (plastic accomodation of the volumic variation and the shear).

A micromechanical approach by finite elements for a transformation without shear [25] let also conclude that transformation plasticity can be considered as an additional strain in the macroscopic constitutive law of the material. The transformation plasticity strain was found to depend linearly on the macroscopic stress deviator (for constant or linearly increasing and decreasing applied stresses and not too small transformed fractions).

For martensitic transformation, first results obtained by a micromechanical model that takes into account both mechanisms but also formation of self accommodating plates [17], seems to show a similar relationship (under a constant non uniaxial loading).

In addition, recent experiments under multiaxial loadings [26] may bring some new elements to that discussion.

\section{THERMOMECHANICAL BEHAVIOUR LAW OF THE MATERIAL}

The modelling of the thermomechanical behaviour of a material that undergoes a phase transformation can be considered in three aspects :

- a metallurgical aspect : the microstructural evolutions of the material for the different thermal histories to which it will be submitted must be described

- a mechanical aspect : the elastic and plastic (or viscoplastic) behaviour of the multiphase material must be known at the different temperatures

- the interactions between stresses/strains and phase transformations must be taken into account.

These last years, different models for calculating the kinetics of phase transformations in steels during continuous cooling and heating have been developed [9, 20, 27-33] and associated with the thermomechanical behaviour law of the material in order to predict heat treatment residual stresses.

In the following we will only describe briefly the constitutive equation that is the most commonly used. Details on the formulations can be found in the references.

\subsection{Modelling}

The macroscopic constitutive equation that governs the behaviour of a material undergoing a phase transformation is generally written by assuming that the total strain rate is an addition of different contributions:

$$
\dot{\varepsilon}_{\mathrm{ij}} \mathrm{t}=\dot{\varepsilon}_{\mathrm{ij}}^{\mathrm{e}}+\dot{\varepsilon}_{\mathrm{ij}} \mathrm{th}^{\mathrm{th}}+\dot{\varepsilon}_{\mathrm{ij}} \mathrm{tr}^{\mathrm{r}}+\dot{\varepsilon}_{\mathrm{ij}} \mathrm{tp}+\dot{\varepsilon}_{\mathrm{ij}}{ }^{\mathrm{in}}
$$

$\dot{\varepsilon}_{\mathrm{ij}} \mathrm{e}$ is the elastic strain rate which is related to the stress rate by Hooke's law. Young's modulus and Poisson's ratio have to be taken temperature dependent and microstructure dependent. (Here, "microstructure" means "volume fractions of the different phases").

$\dot{\varepsilon}_{i j}$ th is the thermal strain rate that takes into account the thermal expansion coefficients of the different phases and their dependence on temperature.

$\dot{\varepsilon}_{\mathrm{ij}} \mathrm{tr}$ is the strain due to the volume change associated with the different phase transformations.

$\dot{\varepsilon}_{\mathrm{ij}}$ tp is the trasformation plasticity strain rate

$\dot{\varepsilon}_{\mathrm{ij}}{ }^{\mathrm{in}}$ is the inelastic strain rate : 
- either the plastic strain rate when no viscous effects are considered. It is calculated using the classical theory of plasticity with the associated hardening rules (isotropic and/or kinematic) $[6,20,27,34,40]$ or obtained from a micro-macro approach $[23,35]$

- or the viscoplastic strain rate $[21,22,36-39]$.

All material parameters (yield stress, hardening parameters, strain rate sensitivity...) are to be considered as temperature and microstucture dependent. Mixture rules are generally assumed.

In addition, it should be mentioned that to take into account hardening is quite complex if a phase transformation occurs. Models have been proposed in order to take into account some possible "recovery" of strain hardening during a phase transformation, i.e.the fact that the newly formed phase remembers only part or even nothing of the previous hardening [22, 23, 34].

\subsection{Application to a tensile test during phase transformation}

The above described material behaviour law has been incorporated in various finite element programmes in order to calculate the internal stresses and strains during the heat treatment of a steel part. Eventhough numerous studies have dealt with the experimental validation of such calculations on heat treated parts, the ability of this type of law to represent the thermomechanical behaviour of a specimen in a much simpler case (for instance a tensile test) has been rarely analysed [41, 42]. This approach will be further illustrated in the following.

Figure 1 shows the mechanical behaviour of a Fe- $0.2 \% \mathrm{C}$ alloy measured during cooling (the cooling rate is constant $0.5^{\circ} \mathrm{C} / \mathrm{s}$ ) and during tensile tests performed at various deformation rates [41]. During cooling, the flow stress of austenite increases as temperature decreases. From $770^{\circ} \mathrm{C}$, softening appears in two domains that correspond to the austenite-ferrite and austenite-pearlite transformations. Softening is quite dependent on deformation rates. The behaviour in the transformation range has been explained by analysing the possible origins of the softening and by quantifying them mainly :

- the variation of the mechanical properties (ferrite has a lower flow stress than austenite in the studied temperature range)

- the volume change associated with the transformation

- the transformation plasticity deformation

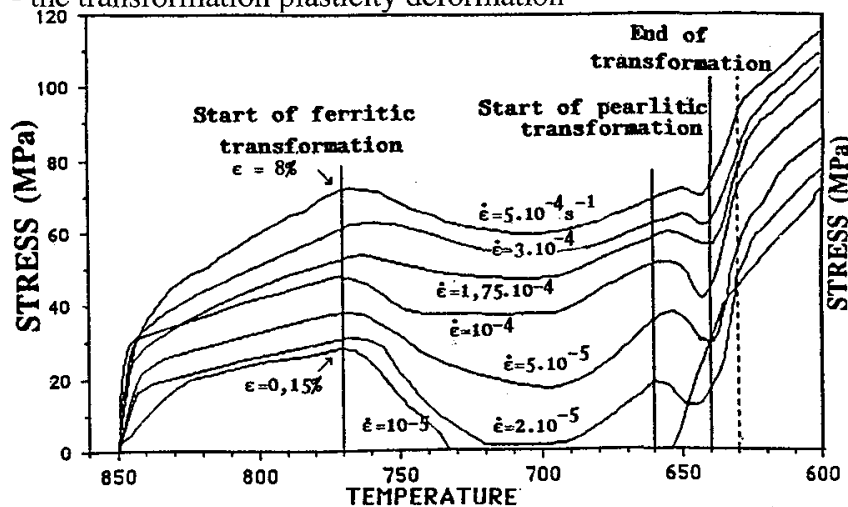

Figure 1: Stress variations versus temperature during the cooling of a $\mathrm{Fe}-0.2 \mathrm{C}$ steel

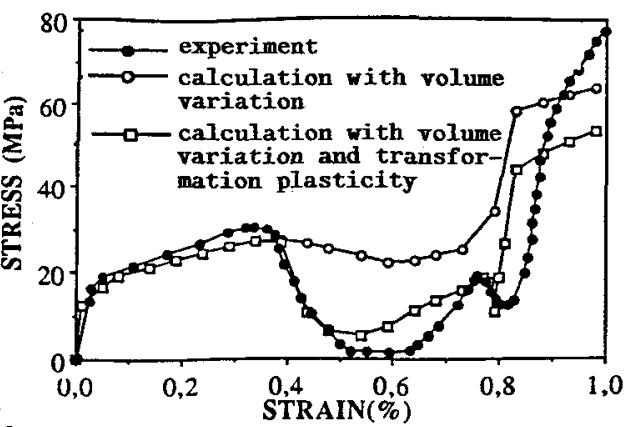

Figure 2: Calculated and measured stress variations versus deformation $\varepsilon=210^{-5} \mathrm{~s}^{-1}$

For example, calculated results (here with an analytical model [41]) show clearly (figure 2) that for a small deformation rate, transformation plasticity is the main contribution to the softening of the alloy. In fact, it has been shown that the amplitude of softening depends largely on the ratio between deformation rate and transformation rate. For a same transformation rate, a small deformation rate will lead to a large softening; at the opposite, a large deformation rate will limit the softening and may even lead to hardening of the phase mixture. A more thorough analysis of these results can be found in [41].

More recently, a similar study has been performed for a low alloyed steel focusing on the bainitic tranformation [14]. As previously, the mechanical behaviour of the individual phases has been determined by tensile tests at different temperatures. In addition, the behaviour has been measured either during isothermal transformation or continuous cooling transformation. These results have been compared to calculated ones using different models. Figure 3 shows a tensile test during continuous cooling at constant deformation rate. The experimental curve shows two domains in which some softening appears. They are 
correlated to the transformation austenite-ferrite (that starts at $48 \mathrm{~s}$ ) and to the transformation austenitebainite (at 100s). The martensitic transformation (at 160s) does not lead to stress relaxation.

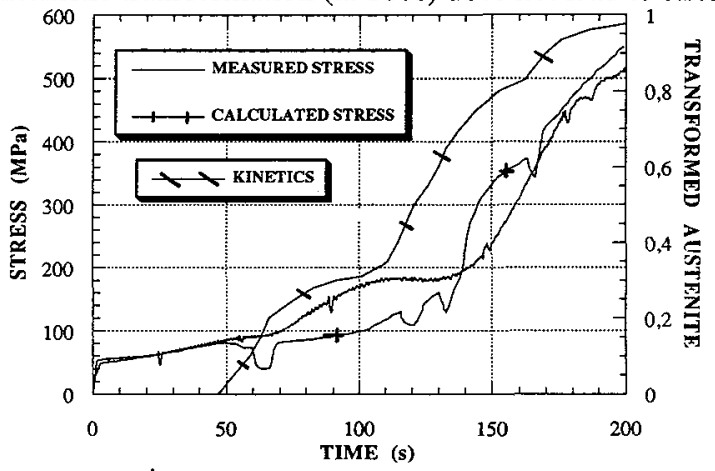

Figure 3: Stress variations versus time and phase transformation kinetics during continuous cooling Experiment+Calculation (with the finite element software described in [43])

The calculated curve has been obtained using a thermoelastoplastic behaviour law of the material with isotropic hardening and "loss of memory" during phase transformation [43]. The calculation describes very well the behaviour' of austenite and shows well the stress relaxations in the transformation domains. Nevertheless, these stress relaxations are overestimated. Moreover, the stress level reached by the mixture austenite+ferrite is underestimated by the calculation.

A calculation has also been performed with the behaviour law proposed by Leblond [23]. The result is given on figure 4 . Although this model gives a similar description of the material behaviour in the austenitic domain and during the austenite-ferrite transformation as the previous one, it does not show a stress relaxation associated with the bainitic transformation.

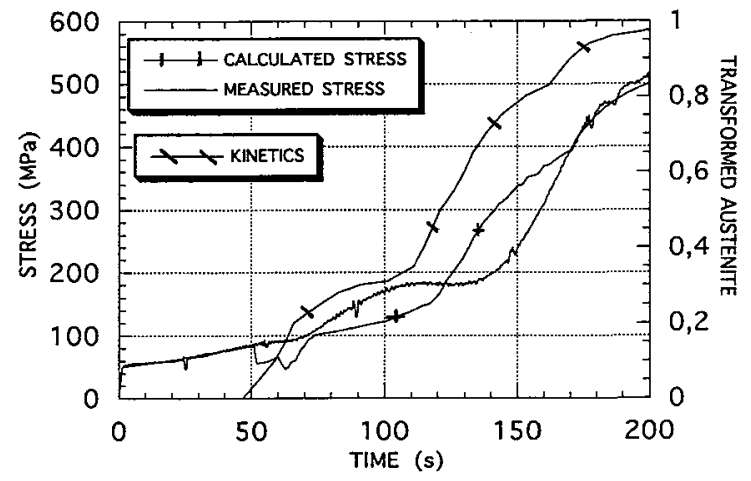

Figure 4: Stress variations versus time and phase transformation kinetics during continuous cooling Experiment + Calculation (with the finite element code SYSWELD [44])

Although the complete analysis of all the results cannot be given here, our results have shown that the used macroscopic constitutive law allows a correct qualitative description of the material behaviour. Nevertheless, an accurate quantitative description is much more difficult to achieve because it depends highly on the accuracy of the input data, essentially the kinetics of the transformations and the mechanical properties of the individual phases (that are temperature dependent but also morphology dependent [41]).

\section{CALCULATION OF HEAT TREATMENT INTERNAL STRESSES}

The calculation of heat treatment internal stresses includes the calculation of the temperature distributions in the piece during the treatment (solution of the heat equation) coupled with the calculation of the microstructural evolutions followed by the solution of the mechanical problem (equilibrium of stresses, compatibility of strains with suitable boundary conditions) by the finite element method. In some cases, the coupling between stress/ strain and microstructural evolutions is also taken into account.

In addition, all the input data concerning both the material behaviour (transformation kinetics, thermophysical properties, mechanical properties...) and the heat treatment process (heat flux densities...) 
have to be determined. Many authors have developed such an approach. The aim was on one hand to understand better the development of internal stresses all along the treatment and on the other hand to validate experimentally the results of the calculation (mainly by comparing calculated and measured residual stress profiles). Hereafter, we will try to give some general ideas on the role of stress-phase transformation interactions in the prediction of residual stresses and illustrate them by examples.

\subsection{Effect of the mechanical interaction}

The most thorough analyses of the role of transformation plasticity on the development of internal stresses have been performed about ten years ago [34, 40, 45-49]. Some more recent studies can also be mentioned $[50,51]$. The main points are reported below [3].

\subsubsection{Effect on the stress/strain evolutions}

During a heat treatment stresses arise due to the thermal gradients generated in the piece during cooling (case of quenching) or during heating and cooling (case of surface heat treatment) and to the phase transformations that occur at the different locations in the piece. Chemical gradients of the piece (as the ones generated during thermochemical treatments) will also intervene.

The stress evolution at a given location in the piece can generally be decomposed in periods where the material is loaded either in tension or in compression and periods where unloading occurs. Particularly as a phase transformation occurs, the associated volume change induces unloading. During loading, the stresses are generally high enough to produce plastic strains.

For example, figure 5 shows the calculated stress (5a) and plastic strain (5b) evolutions of a cylinder during martensitic quenching in cold water. In the first stage of cooling, the surface is under tension ( the center in compression) due to the thermal gradients alone and plastic strains occur in austenite. As martensitic transformation takes place at the surface (at Ms) immediately unloading occurs due to the volume increase. Transformation plasticity strains accompany the transformation. New plastic strains only occur as the material is submitted to high compressive stresses. In a last stage, the surface is unloaded. While the transformation progresses in the surface area, the center undergoes firstly. unloading in compression. During the further loading in tension, plastic strains are generated; a last stage of unloading due to the martensitic transformation in the center can be observed.
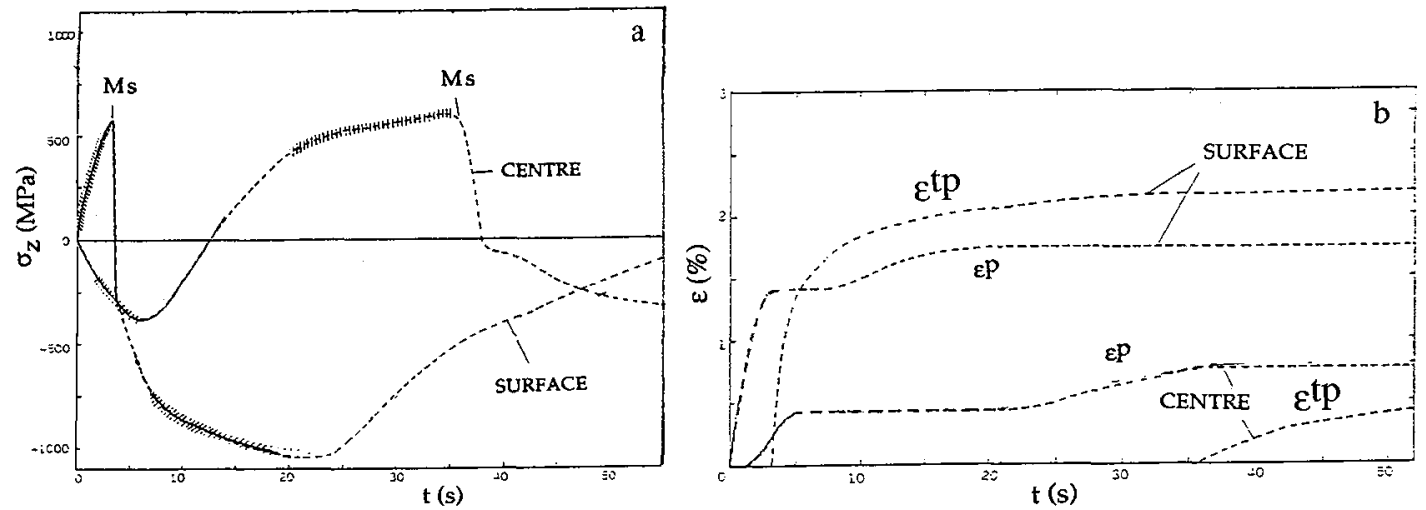

Figure 5: Quenching of a 60NCD11 steel cylinder (35mm in diameter) in cold water.

a.Calculated axial stress evolutions over time at the surface and in the center. //I//// Domains where plastic strains occur

b. Evolutions of the equivalent plastic strain $\left(\varepsilon_{\mathrm{e}} \mathrm{e}^{\mathrm{p}}\right)$ and equivalent transformation plasticity strain $\left(\varepsilon_{\mathrm{e}}{ }^{\mathrm{tp}}\right)$ versus time.

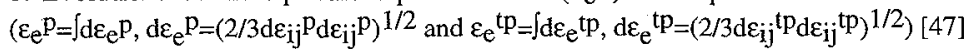

In order to highlight the effect of the transformation plasticity strain, comparisons have been made between calculated results obtained either by taking it into account or not. The analysis showed that :

- as the material is in an elastic regime as transformation occurs, transformation plasticity acts as an additional strain and leads to stress relaxation

- as the material deforms plastically, either transformation plasticity (whose amplitude is transformation rate and stress dependent) is sufficient to accommodate the deformations of the material (no additional plastic strain is necessary) and stress relaxation generally occurs; if transformation plasticity is not sufficient 
further plastic strain is necessary and no stress relaxation occurs. (The stress follows the evolution of the flow stress of the material).

This behaviour is illustrated in figure 6 that shows the "loading paths" (at the surface of a cylinder) during martensitic quenching (same case as in figure 5). This kind of representation $[3,45]$ shows clearly the influence of transformation plasticity both on the stress and strain states. For the calculation that includes transformation plasticity, as the martensitic transformation starts at the surface (at $247^{\circ} \mathrm{C}$ ), the material is unloaded: the equivalent total strain becomes higher and the stress changes quicker from tension to compression. As the transformation progresses (at the surface but also in the inside of the piece) stress relaxation occurs untill $172^{\circ} \mathrm{C}$ (the equivalent stress remains lower than the flow stress of the material). Between $172^{\circ} \mathrm{C}$ and $140^{\circ} \mathrm{C}$, both transformation plasticity strains (whose amplitude decreases due to the decrease in transformation rate) and classical plastic strains occur; the equivalent stress is equal to the flow stress. The unloading between $140^{\circ} \mathrm{C}$ and room temperature is due to the martensitic transformation in the inside of the piece.

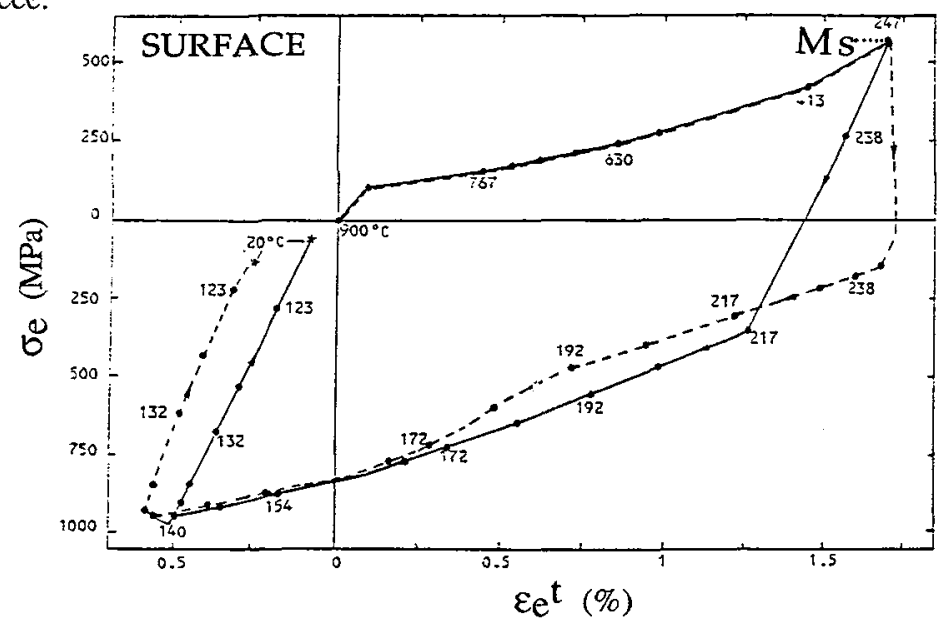

Figure 6: Quenching in cold water of a $60 \mathrm{NCD} 11$ steel cylinder (35mm in diameter) [3]

Calculated "loading path" at the surface. ___ without transformation plasticity - . - - with transformation plasticity $\left(\varepsilon_{\mathrm{e}}^{\mathrm{t}}=\left(2 / 3 \mathrm{~d} \varepsilon_{\mathrm{ij}}{ }^{\mathrm{t}} \mathrm{d} \varepsilon_{\mathrm{ij}}\right)^{\mathrm{l}}\right)^{1 / 2}$ is the equivalent total strain, $\sigma_{\mathrm{e}}$ is the equivalent stress)

\subsubsection{Effect on residual stress states}

Whereas the introduction of transformation plasticity will always modify the stress and strain states during the phase transformation, its effect on the residual stress states will be more or less significant depending on each particular case. Indeed, the residual stress states in a piece depend highly on the irreversible strains (plastic strains and transformation plasticity strains) that are generated all along the treatment. Particularly, the relative amplitudes of the irreversible strains that are generated as the material is in tension or in compression are determinant.

For surface heat treatments (like induction or laser hardening) in which only the surface area undergoes a martensitic transformation during cooling, transformation plasticity generally induces stress relaxations during the whole transformation process. Transformation plasticity is able to accommodate alone the deformations of the material. Finally it leads to much lower compressive residual stresses in the hardened zone.

For example, figure 7 shows the transverse stress evolution during heating and cooling at the surface of a laser hardened plate (7a) and the corresponding residual stress distribution (7b) : the stress relaxation effect due to transformation plasticity during martensitic transformation appears clearly. Moreover, a good agreement between calculated results (including transformation plasticity) and residual stress measurements was found in the hardened zone [52]. Similar results have been reported in literature either for laser hardening $[53,54]$ or induction hardening [55].

The above analysis holds also in the case of thermochemical treatments that involve quenching after the diffusion treatment. Results obtained [56] for a case hardening treatment (figure 8) showed that the inclusion of transformation plasticity is of great importance for the prediction of the residual stress levels. 

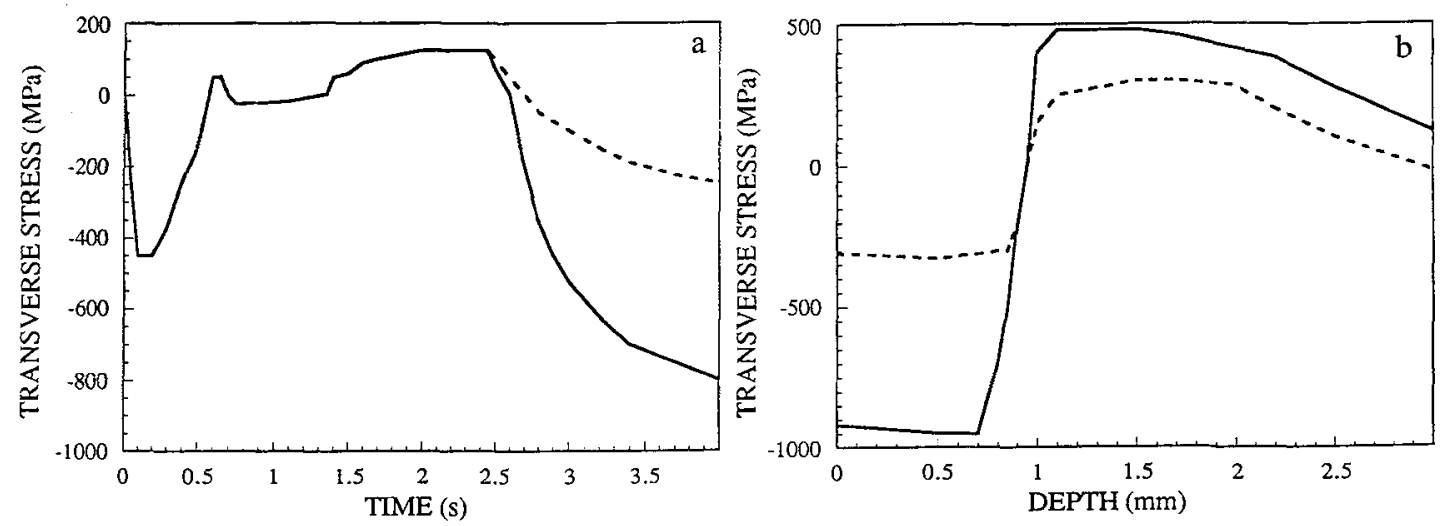

Figure 7: Laser surface hardening of a $0.42 \% \mathrm{C}$ steel plate [52]

a. Calculated stress evolutions at the surface in the middle of the laser track

b. Residual stress distributions versus depth in the middle of the laser track - without transformation plasticity - . - . - with transformation plasticity (the transverse stress is the stress perpendicular to the laser beam displacement)

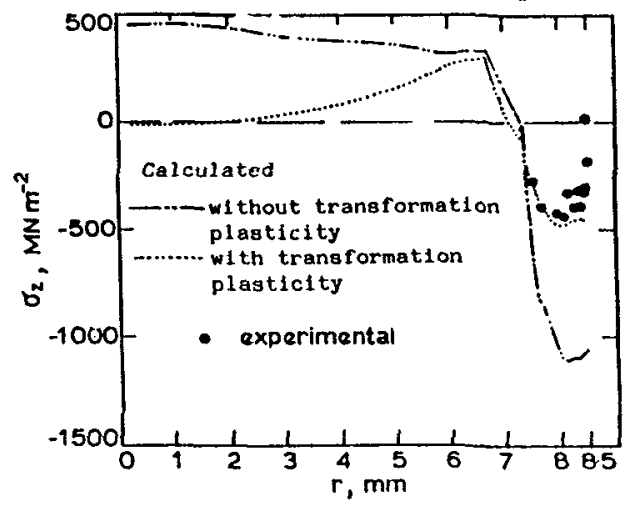

Figure 8: Carburizing and quenching in oil of a SIS2511 steel cylinder [56] Calculated residual stress distributions

If we consider now quenching, we can find a number of results in literature where the authors have compared residual stress profiles that are obtained either by taking transformation plasticity into account or not. Most of these results concern martensitic quenching. The analysis can be the following [3]:

- firstly, if we consider the most simple case of quenching of a material in which no phase transformation occurs, only thermal stresses (due to thermal gradients) are generated and the residual stress profiles are generally characterized by compressive stresses at the surface and tensile stresses in the center (we consider here only simple shaped pieces like cylinders or plates).

- Secondly, if in addition the material undergoes martensitic transformation, the residual stress profile will tend to invert : surface stresses will tend to go to tension and the stress state in the center will tend to become compressive. This analysis was proposed very early in the qualitative approach by Rose et al. [57]. From the numerical approaches, it came out that these tendencies are highly dependent on the irreversible strain histories i.e. on the temperature evolutions in the piece (depending on the quenching medium, on the size of the piece) and on the nature of the steel (Ms temperature, mechanical properties for instance).

- Third, by the introduction of transformation plasticity strains the above mentioned tendencies will be enhanced. The enhancement will generally be larger when no classical plastic strains are generated at the location where transformation takes place.

As an illustration, figure 9 gives the calculated residual stress profiles for martensitic quenching in cold water of a steel cylinder (same case as in figure 5 ). By taking into account only the volume change and the variations of mechanical properties due to the transformation (full line) the residual stress levels are small. When transformation plasticity is included, the residual stress profile gains a more typical shape (tensile stresses in the surface area, compressive stresses in the center). Another example is the quenching in oil of 
a steel plate [45] (figure 10). Here, the inclusion of transformation plasticity leads to a complete inversion of the residual stress profile.

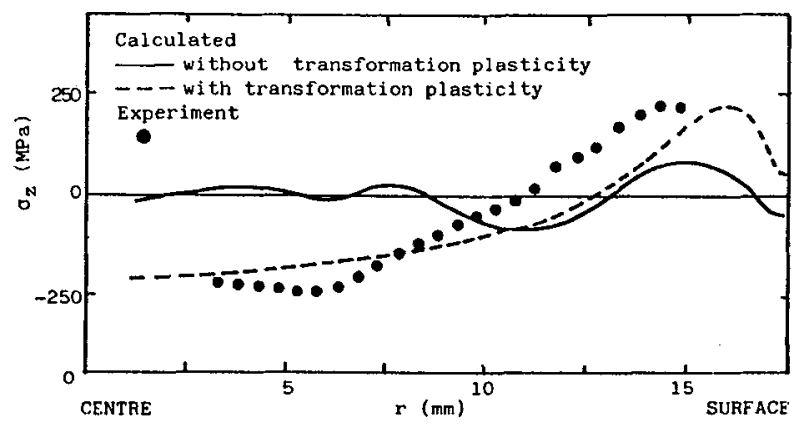

Figure 9: Quenching in cold water of a 60NCD11 steel cylinder (35mm in diameter) [3] Residual stress distributions

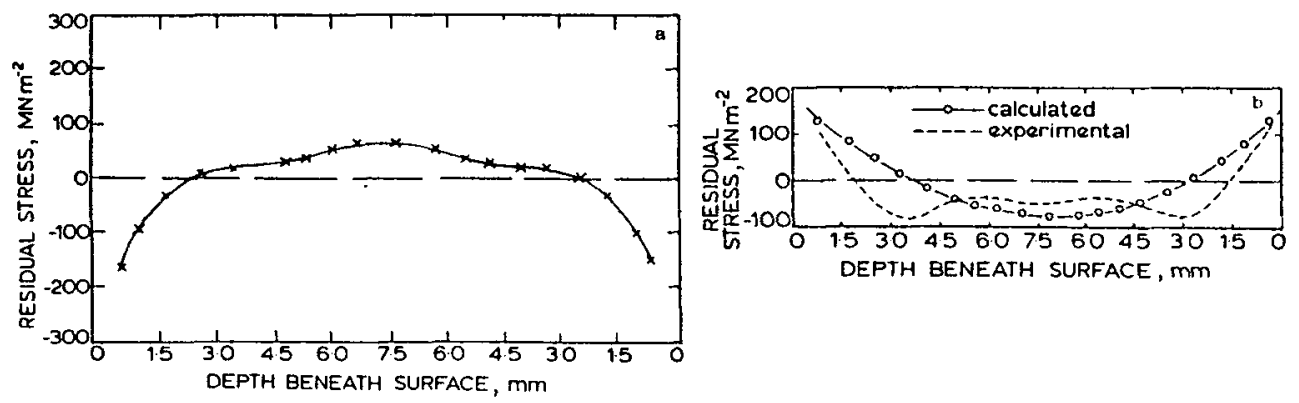

Figure 10: Oil quenching of a $835 \mathrm{M} 30$ steel plate (thickness $15 \mathrm{~mm}$ ) [45]

Residual stress distributions a. - without transformation plasticity b.0-00. with transformation plasticity

Only few results exist concerning the effect of transformation plasticity when the heat treatment involves high temperature transformations. Figure 11 illustrates this effect in the case of pearlitic "quenching" of a cylinder [43]. The small plastic strains that develop during cooling, as the steel is austenitic, lead to a residual stress profile with small compressive stresses at the surface (full line). Transformation plasticity brings an additional irreversible strain and leads to the inversion of the residual stress profile (dotted line).
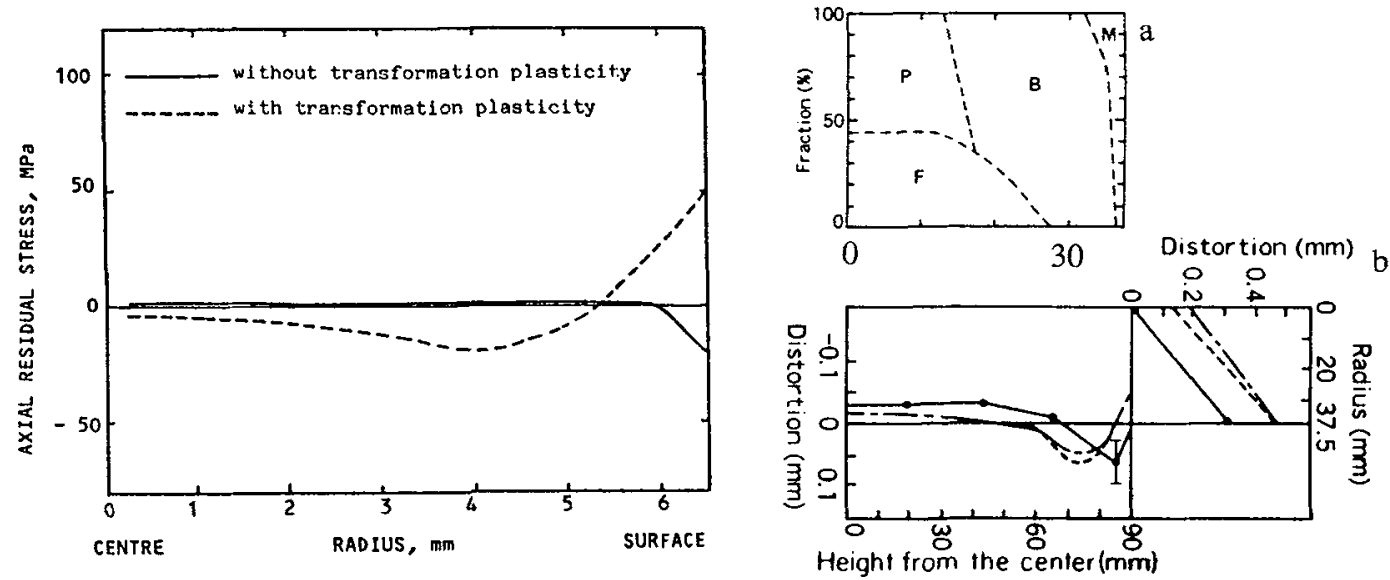

Figure 11: Cooling $\left(14^{\circ} \mathrm{C} / \mathrm{s}\right)$ of an eutectoid carbon steel cylinder (diameter $13 \mathrm{~mm}$ ) [43].

Residual stress profiles
Figure 12: Quenching of a 1035 steel bar (75mm diameter)[51]

a. Radial profiles of microstructure at midlength

b. Distortions ------- without transformation plasticity

- - - with transformation plasticity 
Finally it should be mentioned that in welding processes of steels the phenomena occuring in the heat affected zone are the same as during a heat treatment. Thus, transformation plasticity will affect the stress/strain evolutions during cooling and have an effect on the residual stress distributions that depends on the analysed conditions [58-60].

\subsubsection{Effect on distortions}

Of course, the final mechanical state of a piece after heat treatment is not only characterized by residual stress distributions but also deformations of the piece. The effect of transformation plasticity on the distortions of a heat treated piece has been less studied [45, 48, 51, 61]. Again, the more or less important effect of transformation plasticity on distortions will depend on each particular heat treatment process. For martensitic quenching of cylinders it has been shown [48] that the inclusion of transformation plasticity enhances a concave-type deformation of the cylinder. It should be recalled that thermal stresses only would lead to a convex-type deformation and that the occurence of martensitic transformation will tend to give a concave type deformation of the cylinder [62]). More recently, for quenching of steel bars, only slight differences have been observed when the distortion is calculated with the transformation plasticity strain considered both for martensitic quenching and for quenching involving various transformations during cooling as shown in figure 12 [51].

From all these results, it is now well admitted that any residual stress analysis for materials that undergo phase transformations must include transformation plasticity.

In most of the studies the agreement with experimental results was found to be more satisfactory if considering transformation plasticity. Nevertheless some authors $[46,48]$ concluded on better simulation results in comparison with experiments (for martensitic quenching) by limiting the amplitude of transformation plasticity considered in the model It should also be mentioned that only few results have been reported on complex shaped pieces [61, 63-65].

From our point of view, the discussion on the possible reasons of discrepancies between calculated results and experimental ones is difficult : the calculated results depend on one hand on the material behaviour model and the associated input data and on the other hand on the process parameters. To obtain the data on the thermomechanical behaviour of the material is a hard experimental work and some data have to be extrapolated (for example from high temperature variations to lower temperatures). Moreover, the modelling of the process is complex, particularly the quenching process due to the heat transfer mechanisms that are difficult to control. This problem becomes even more acute for industrial pieces.

\subsection{Effect of the metallurgical interaction}

Very few results have been obtained by taking into account in the model the coupling between the internal stress states generated in a piece during heat treatment and the transformation kinetics [6, 43]. This coupling will, of course, affect the transformation kinetics at the different locations in the piece and consequently the temperature evolutions (through the latent heat associated with the transformation) and the stress/strain evolutions. The residual stress state may be also affected.

\subsubsection{Effect on transformation kinetics}

If we refer to the models (2.1.2), the effect of the stresses on the transformation kinetics will depend on the type of transformation and on the stress state in the piece, at the location where the transformation occurs.

Concerning martensitic transformation, we expect that the transformation in the piece starts earlier during cooling when the material is submitted to tensile stresses (Ms temperature is increased) or starts later if compressive stresses with a relatively large hydrostatic component are present. For middle size pieces, generally an increase in Ms temperature has been calculated. During further cooling, the progress of the transformation is slowered due to the mechanical unloading of the material that is concomitant with the transformation (the mechanical driving force for the transformation decreases). For example, figure 13 shows the evolution of the volume fraction of martensite versus temperature in a quenched cylinder (case of figure 5). The effect of the internal stresses appears in the first stages of transformation (until $25 \%$ martensite formed). It is more pronounced in the center of the piece due to a higher contribution of the hydrostatic (tensile) stress. These modifications in the transformation progress have a negligible effect on the temperature evolutions in the piece. 


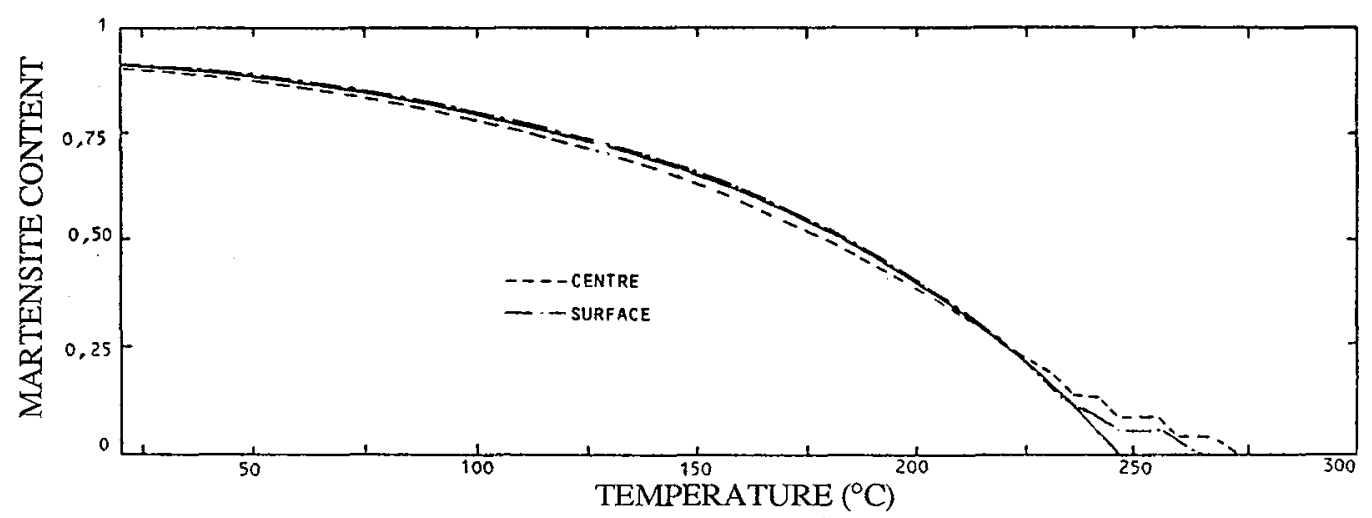

Figure 13: Quenching in cold water of a $60 \mathrm{NCD} 11$ steel cylinder $(35 \mathrm{~mm}$ in diameter) $[1,3]$

Calculated progress of martensitic transformation versus temperature _- _- without effect of internal stresses -. - with effect of internal stresses

For diffusion dependent transformations, the transformation kinetics are generally accelerated. In the example of the cooling down of a cylinder in which only a pearlitic transformation occurs (figure 14) a shortening of the incubation period and an increase in transformation rate is clearly observed at the surface when the metallurgical interaction is included (14a). These effects are much smaller in the center due to a lower level of the stress as the transformation starts. Due to these kinetics changes the temperature evolutions in the piece are highly modified. Particularly, the recalescence starts earlier and has a lower amplitude (figure 14b). A more thorough analysis of these results and a discussion of the proposed model (2.1.2) can be found in [7].
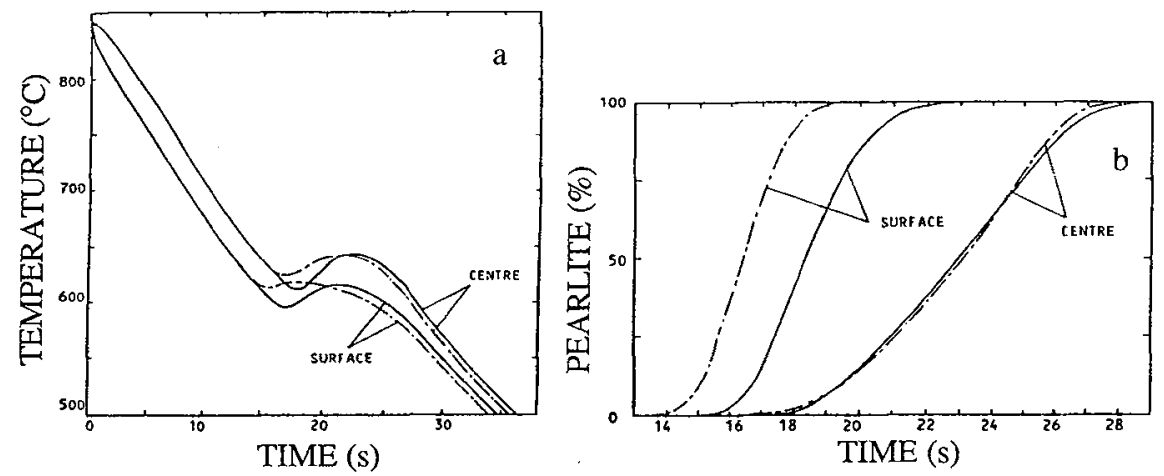

Figure 14: Cooling down $\left(14^{\circ} \mathrm{C} / \mathrm{s}\right)$ of an eutectoid carbon steel cylinder (13mm diameter) [43].

Calculated cooling curves (a) and pearlitic transformation kinetics (b)

- without effect of internal stresses - . - - with effect of internal stresses

The effect of stresses on transformation kinetics may have important practical consequences :

- the hardness distributions in the piece can be modified. Figure 15 shows a comparison between calculated hardness profiles after pearlitic quenching considering or excluding the metallurgical interaction.

- When a fully pearlitic microstructure is looked for (for example in steel wires), generally a low interlamellar spacing i.e. low transformation temperature must be obtained. The numerical simulations allowed to show that as soon as the thermal gradients become high, the increase in the cooling rate is less efficient in order to decrease the transformation start temperature. The transformation start temperature increases with the diameter of the wire for a given cooling rate (due to higher internal stresses) as can be seen on figure 16. 


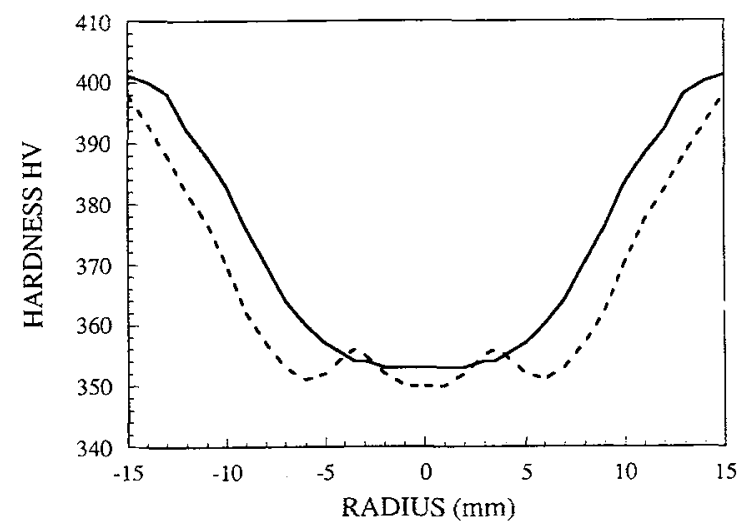

Figure 15: Quenching (in a polymer solution) of an eutectoid carbon steel cylinder ( $30 \mathrm{~mm}$ diameter) [66]

Hardness distributions — without effect of internal stresses - . - with effect of internal stresses

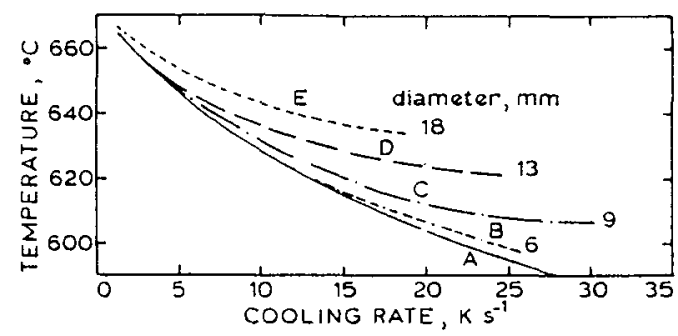

Figure 16: Calculated transformation start temperature as a function of cooling rate and wire diameter [67] A without effect of internal stresses B-E with effect of internal stresses

\subsubsection{Effect on stress/strain evolutions and on residual stresses}

As the deformations of the material during a heat treatment are highly dependent on transformation rate, we expect that the changes in transformation kinetics described above will affect the stress/strain evolutions : - For martensitic quenching, the main effect is a shift (in the time scale) of the stress evolutions (shown in figure 5) due to the increase in Ms temperature. For the same reason, a small shift (in deformation scale) of the loading path (figure 6) has been observed [3]. The consequences on the residual stress distributions are relatively small (figure 17 ).

- For pearlitic "quenching", the acceleration of transformation kinetics resulted in an enhancement of the variations that were already depicted by the introduction of transformation plasticity. Thus, the calculated residual stress profile (figure 18) shows higher tensile stresses at the surface and higher compressive stresses in the center due to higher amplitudes of transformation plasticity strains [43].

Results on quenching of a carbon steel cylinder [6] seems showing the same tendency (figure 19). (Note that no transformation plasticity was included in these calculations).

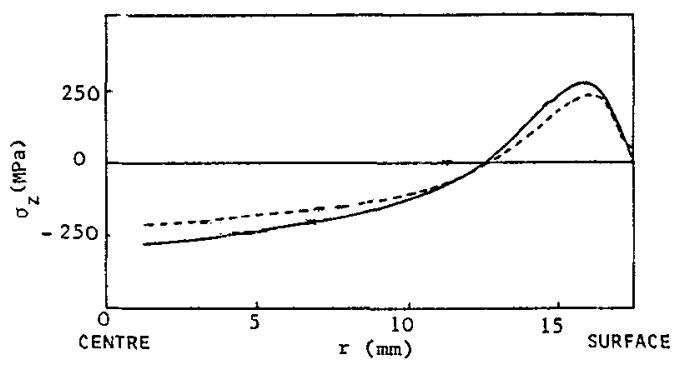

Figure 17: Quenching in cold water of a 60 NCD 11 steel cylinder (35mm diameter) [1,3]

Calculated radial residual stress profiles

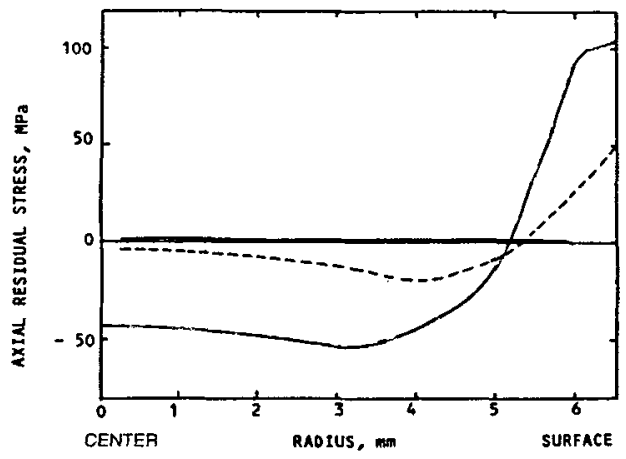

Figure 18: Cooling down $\left(14^{\circ} \mathrm{C} / \mathrm{s}\right)$ of an eutectoid carbon steel cylinder (13mm diameter) [43] Calculated radial residual stress profiles ----- without effect of internal stresses on transformation kinetics with effect of internal stresses on transformation kinetics

From these results (unfortunately very few), it is difficult to put a final statement on the importance of the metallurgical interaction in the prediction of heat treatment residual stresses.

It seems that in most cases of quenching, the metallurgical interaction does not influence significantly the residual stress states, even if it affects locally the stress evolution. Nevertheless, in some specific cases (where high temperature transformations occur) a more significant effect has been evidenced, that cannot be neglected (particularly on the transformation kinetics). This has been confirmed more recently by residual stress and distorsion calculations performed for more complex shaped pieces $[64,65]$. 

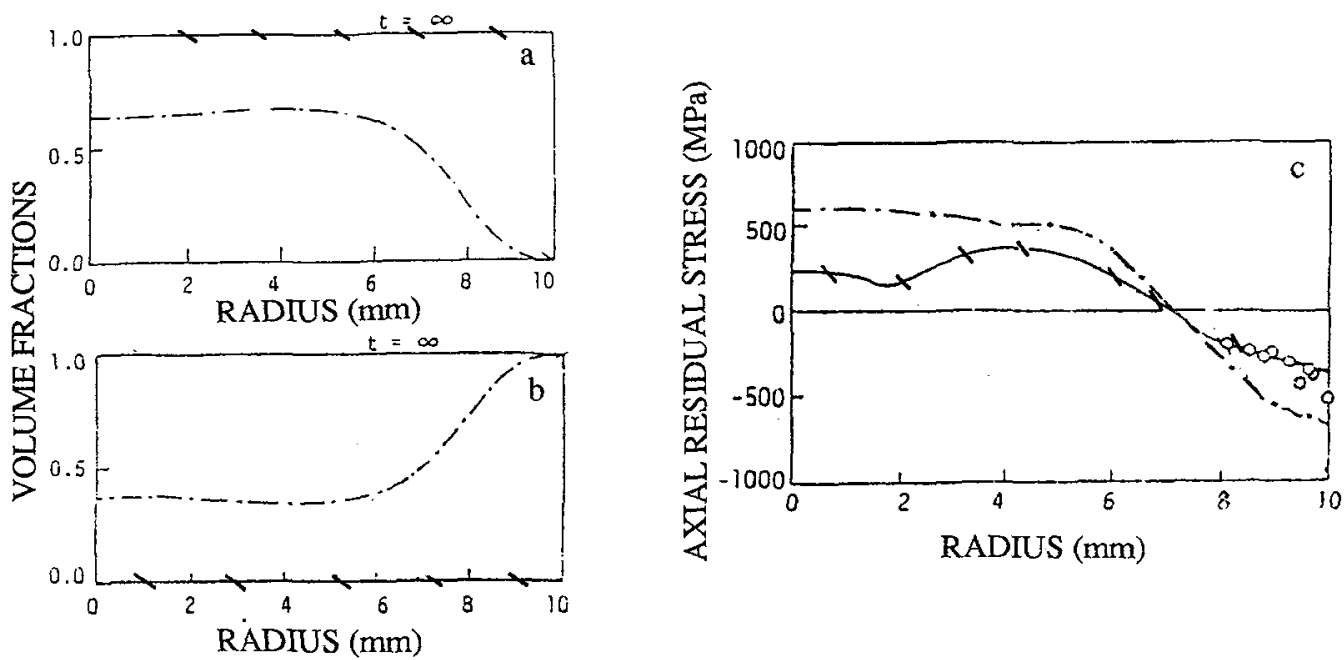

Figure 19: Water quenching of a carbon steel (S45C) cylinder (20mm diameter) [6]

Calculated distributions of microstructures a. pearlite b. martensite.

Calculated residual stress distributions (c) (o experimental values)

- - without effect of internal stresses on transformation kinetics

+ with effect of internal stresses on transformation kinetics

\section{CONCLUSIONS}

The macroscopical behaviour law of a material undergoing phase transformations has been recalled. Particularly, the modelling of the stress - phase transformation interactions (transformation plasticity and the effect of internal stresses on transformation kinetics) has been described.

The main conclusions are:

- the macroscopical approach that is the most commonly used for calculating heat treatment stresses and strains and that considers transformation plasticity as an additional deformation in the behaviour law of the material allows to describe the mechanical behaviour of a specimen for different types of transformations (ferritic, pearlitic, bainitic, martensitic) in anisothermal conditions.

- The effect of stress - phase transformation interactions on the residual stress distributions and on the distortions can generally not be forecasted à priori as they depend highly on the local stress states in the piece when transformation occurs. Thus, coupled temperature-phase transformation-stress/strain calculations have to be performed. It is the only way to analyse the influence of the material behaviour on the result of the treatment, for given heat treatment conditions, and eventually to neglect some minor effects for a given application.

\section{Aknowledgments}

I am very grateful to A. Simon who initiate my activity for useful improvements and comments and to $\mathrm{E}$. Gautier for the years of collaboration and fruitful discussions.

Many students have contributed to this research field: C. Basso, F.M.B. Fernandes, D. Farias, F. Saliou ${ }^{\dagger}$, L. Massicart, M. Zandona, M. Boufoussi, A. Mey.

I wish also to mention the fruitful collaboration with S. Sjöström (Linköping University).

This research field has been supported by ARBED, CETIM, PSA, RENAULT, UNIMETAL RECHERCHE...I thank especially RENAULT for providing non published results.

\section{References}

[1] Denis S., Gautier E., Simon A., Beck G., Material Science and Technology 1 (1985) 805-814

[2] Gautier E.," Transformations perlitique et martensitique sous contrainte de traction dans les aciers", Thèse de Doctorat d'Etat, INPL Nancy 1985

[3] Denis S., "Modélisation des interactions contrainte-transformation de phases et calcul par éléments finis de la genèse des contraintes internes au cours de la trempe des aciers", Thèse de Doctorat d'Etat, INPL Nancy 1987 
[4] Denis S., Gautier E., Simon A., "Modelling of the mechanical behaviour of steels during phase transformation : a review", ICRS2, Nancy 23-25 Nov. 1988, G. Beck, S. Denis, A. Simon Eds (Elsevier Applied Science 1988 ) pp. 393-398

[5] Gautier E., Zhang J.S., Zhang X.M., "Martensitic transformation under stress in ferrous alloys. Mechanical behaviour and resulting morphologies", ICOMAT, Lausanne 20-25 Aug.1995, Journal de Physique (to be published)

[6] Inoue T., Wang Z.G., "Finite element analysis of coupled thermoinelastic problem with phase transformation", Int. Conf. Num. Meth. in Industrial Forming Processes, Swansea 1982, J.F.T. Pittmann, R.Wood, J.H. Dand Alexander Eds (Pineridge Press 1982)

[7] Denis S., Gautier E., Sjöström S., Simon A., Acta Met. 35 (1987) 1621-1632

[8] Loshkarev V.E., Metal Science and Heat Treatment 28 (1986) 3-9

[9] Denis S., Farias D., Simon A., ISIJ International 32 (1992) 316-325

[10] Gautier E., Zhang X.M., Simon A., "Role of internal stress state on transformation induced plasticity and transformation mechanisms during the progress of stress induced phase transformation", ICRS2, Nancy 23-25 Nov. 1988, G. Beck, S. Denis, A. Simon Eds (Elsevier Applied Science 1988 ) pp.777-783

[11] Gautier E., Simon A., Beck G., Acta Metall. 35 (1987) 1367-1375

[12] De Jong M., Rathenau G.W., Acta Metall. 7 (1959) 246-253

[13] Matsuzaki A., Bhadeshia H.K.D.H., Harada H., "Effect of stress on bainitic transformation in Fe-SiMn-C alloy", ICOMAT'92, Monterey 20-24 July 1992, C.M. Wayman and J. Perkins Eds (Monterey Institute for Advanced Studies 1993)

[14] Gautier E., Denis S., "Comportement thermomécanique d'un acier au cours de la transformation bainitique", Report RENAULT, 1995

[15] Ganghoffer J.F., Simonsson K., Denis S., Gautier E., Sjöström S., Simon A., Journal de Phys. Coll. C3 4 (1994) 215-220

[16] Marketz F., Fischer F.D., "A micromechanical study of the deformation behaviour of Fe-Ni alloys and martensitic transformation", PTM 94 Solid Solid Phase Transformation, Johnson W.C., Howe J.M., Laughlin D.E., Soffa W.A. Eds ( TMS 1994) 785-790

[17] Simonsson K., "Micro-mechanical FE-simulations of the plastic behaviour of steels undergoing martensitic transformation", Dissertation N³62 Linköping 1994

[18] Wen Y., Denis S, Gautier E., ibid

[19] Franitza S., "Zur Berechnung der Wärme- und Umwandlungsspannungen in langen Kreiszylindern", Dissertation TU Braunschweig 1972

[20] Giusti J., "Contraintes et déformations résiduelles d'origine thermique. Application au soudage et à la trempe des aciers.", Thèse de Doctorat d'Etat, Univ. Pierre et Marie Curie Paris 1981

[21] Hamata N., "Modélisation du couplage entre l'élasto-viscoplasticité anisotherme et la transformation de phase d'une fonte G.S. ferritique", Thèse de Doctorat, Univ. Paris 61992

[22] Videau J.C., Cailletaud G., Pineau A., Journal de Phys. IV Colloque C3 4 (1994) 227-232

[23] Leblond J.B., Int. Journal of Plasticity 5 (1989) 573-591

[24] Fischer F.D., European Journal Mech. AV Solids 11 (1992) 233-244

[25] Sjöström S., Ganghoffer J.F., Denis S., Gautier E., Simon A., Eur. J. Mech. A/Solids 13 (1994) 803-817

[26] Videau J.C., Cailletaud G., Pineau A., ibid

[27] Graja P., Scholtes B., Müller H., Macherauch E., "Residual stress distributions in cylindrical parts due to continuous and discontinuous hardening processes", ICRS, Garmisch-Partenkirchen 1986, E. Macherauch and V. Hauk Eds (DGM 1987)

pp. 687-694

[28] Hildenwall B.,"Prediction of residual stresses created during quenching", Dissertation N³9, Linköping University 1979

[29] Melander M., "Computational and experimental investigation of induction and laser hardening", Dissertation $\mathrm{N}^{\circ} 124$, Linköping University 1985

[30] Leblond J.B., Devaux J., Acta Metall. 32 (1984) 137-146

[31] Hougardy H.P., Wildau M., Stahl u. Eisen 105 (1985) 1289-1296

[32] Waeckel F., Journal de Physique C3 4 (1994) 221-232

[33] Buchmayr B., Kirkaldy J.S., "A fundamental based microstructural model for the optimization of heat treatment processes", 1st Int. Conf. on Quenching and Control of Distortion, Chicago (Illinois) 1992, G.E. Totten Ed. (ASM Intern. 1992) pp. 221-227

[34] Sjöström S., "The calculation of quench stresses in steel", Dissertation $N^{\circ} 84$, Linköping University 1982

[35] Leblond J.B., Devaux J., Devaux J.C., Int. Journal of Plasticity 5 (1989) 551-572 
[36] Rammerstorfer F.G., Fischer F.D., Till E.T., Mitter W., Gründler O., "The influence of creep and transformation plasticity in the analysis of stresses due to heat treatment", Numerical Methods in heat transfer, R.W. Lewis K. Morgan B.A. Schrefler Eds (John Wiley\&Sons Ltd 1983) pp. 447-460

[37] Assaker D., Hogge M., Dubois M., Magnee A., Société Belge des Mécaniciens 1404 (1989) 7.1-7.8

[38] Wang Z., Inoue T., Materials Science and Technology 1 (1985) 899-903

[39] Colonna F., Massoni E., Denis S., Gautier E., Wendenbaum J., Journal of Mat. Proc. Techn. 34 (1992) 525-532

[40] Rammerstorfer F.G., Fischer F.D., Mitter W., Bathe K.J., Snyder M.D., Computers and Structures 13 (1981) 771-779

[41] Liébaut C., "Rhéologie de la déformation plastique d'un acier Fe-C durant sa transformation de phase", Thèse de doctorat INPL Nancy 1988

[42] Gautier E., Denis S., Liébaut Ch., Sjöström S., Simon A., Journal de Phys. C3 4 (1994) 279-284

[43] Denis S., Sjöström S., Simon A., Met. Trans 18A (1987) 1203-1212

[44] SYSWELD, Users Manual, Framasoft + CSI, Lyon (France)

[45] Abbasi F., Fletcher A.J., Material Science and Technology 1 (1985) 830-837

[46] Convert F., Turbat A., "Estimation and experimental determination of residual stresses and distortion in quenched bars", Eigenspannungen, Karlsruhe 1983, Macherauch E., Hauk V.Eds (DGM 1983) pp. 251-277

[47] Denis S., Simon A., "Discussion on the role of transformation plasticity in the calculation of quench stresses in steels", ICRS, Garmisch-Partenkirchen 1986, E. Macherauch and V. Hauk Eds (DGM 1987) pp. 565-572

[48] Desalos Y., Giusti J., Gunsberg F., "Déformations et contraintes lors du traitement thermique de pièces en acier" Report RE902 IRSID, May 1982.

[49] Mitter W., "Umwandlungsplastizität und ihre Berücksichtigung bei der Berechnung von Eigenspannungen", (Gebrüder Bornträger Berlin 1987)

[50] Besserdich G., Scholtes B., Müller H., Macherauch E., "Development of residual stresses and distortion during hardening of SAE 4140 cylinders taking into account transformation plasticity", Residual Stresses, V. Hauk H.P. Hougardy E. Macherauch H.D. Tietz Eds (DGM 1993) pp. 975-984

[51] Nagasaka Y., Brimacombe J.K., Hawbolt E.B., Samarasekera I.V., Hernandez-Morales B., S.E. Chidiac, Met. Trans. 24A (1993) 795-808

[52] Denis S., Boufoussi M., Chevrier J.Ch., Simon A., "Analysis of the development of residual stresses for surface hardening of steels by numerical simulation: effect of process parameters", ICRS4, Baltimore 1994, M.R. James Ed. (Society of Experimental Mechanics Bethel 1994) pp. 513-519

[53] Yang Y.S., Na S.J., J. Heat Treating 9 (1991) 49-56

[54] Bergheau J.M., Pont D., Leblond J.B.,"Three dimensional simulation of a laser treatment through steady state computation in the heat source's comoving frame”, IUTAM Symp., Luleä 1991, L. Karlsson L.E. Lindgren M. Jonsson Eds (Springer Verlag 1992) pp. 85-92

[55] Zandona M., Mey A., Boufoussi M., Denis S., Simon A., "Calculation of internal stresses during surface heat treatment of steels", European Conf. on Residual Stresses, Francfort 1992, V. Hauk, H.P.

Hougardy, E. Macherauch und H.D. Tietz Eds (D.G.M. 1993) pp. 1011-1020

[56] Sjöström S., Material Science and Technology 1 (1985) 823-829

[57] Rose A., Bühler H., Archiv. Eisenhïttenw. 40 (1969) 411

[58] Josefson B.L., Material Science and Technology 1 (1985) 904-908

[59] Oddy A., Goldak J., McDill M., Journal of Pressure Vessel Technology 114 (1992) 33-38

[60] Leblond J.B., Devaux J., Devaux J.C., Soudage et Techniques connexes (1988) 312-324

[61]Anastassiou M. "Distorsions lors de la trempe d'organes de boîte de vitesses", ATTT 1993, Gand 2325 Juin 1993, (PYC Edition) pp. 11-36

[62] Toshioka Y., Material Science and Technology 1 (1985) 883-892

[63]Inoue T., Wang Z.G., Miyao K., " Quenching stress of carburised steel gear wheel", ICRS2, Nancy 23-25 Nov. 1988, G. Beck, S. Denis, A. Simon Eds (Elsevier Applied Science 1988 ) pp. 606-611

[64] Bourdouxhe M., Denis S., Simon A., "Computation of phase changes and deformations in long products undergoing thermal treatments", ICRS3, Tokushima 1991, H. Fujiwara, T. Abe, K. Tanaka Eds (Elsevier Applied Science 1992) pp. 202-207

[65] Colonna F., “"Modélisation numérique du refroidissement de rails”, Thèse de Doctorat de l'Ecole des Mines de Paris (1992)

[66] Saliou F., Zandona M. , S. Denis, E. Gautier, Internal work LSG2M (1991)

[67] Denis S., Basso C., Fernandes F., Simon A., Mém. et Etud. Scient. Revue Métall. (1986) 533-542 